\title{
Personal, social, and environmental correlates of physical activity in adults living in rural south-west England: a cross-sectional analysis
}

\author{
Emma Solomon ${ }^{1 *}$, Tim Rees ${ }^{1}$, Obioha C Ukoumunne ${ }^{2}$, Brad Metcalf ${ }^{1}$ and Melvyn Hillsdon ${ }^{1}$
}

\begin{abstract}
Background: Despite the health risks, physical inactivity is common. Identifying the correlates of physical activity to inform the design of interventions to reduce the disease burden associated with physical inactivity is a public health imperative. Rural adults have a unique set of characteristics influencing their activity behaviour, and are typically understudied, especially in England. The aim of this study was to identify the personal, social, and environmental correlates of physical activity in adults living in rural villages.

Methods: The study used baseline data from 2415 adults (response rate: 37.7\%) participating in the first time period of a stepped-wedge cluster randomised trial, conducted in 128 rural villages from south-west England. Data collected included demographic characteristics, social factors, perception of the local environment, village level factors (percentage male, mean age, population density, Index of Multiple Deprivation, and sport market segmentation), and physical activity behaviour. Random effects ("multilevel") logistic regression models were fitted to the binary outcome whether individuals met physical activity guidelines, and random effects linear regression models were fitted to the continuous outcome MET-minutes per week leisure time physical activity, using the personal, social, environmental, and village-level factors as predictors.
\end{abstract}

Results: The following factors both increased the odds of meeting the recommended activity guidelines and were associated with more leisure-time physical activity: being male $(p=0.002)$, in good health $(p<0.001)$, greater commitment to being more active ( $p=0.002)$, favourable activity social norms $(p=0.004)$, greater physical activity habit $(p<0.001)$, and recent use of recreational facilities $(p=0.01)$. In addition, there was evidence $(p<0.05)$ that younger age, lower body mass index, having a physical occupation, dog ownership, inconvenience of public transport, and using recreational facilities outside the local village were associated with greater reported leisure-time physical activity. None of the village-level factors were associated with physical activity.

Conclusions: This study adds to the current literature on the correlates of physical activity behaviour by focusing on a population exposed to unique environmental conditions. It highlights potentially important correlates of physical activity that could be the focus of interventions targeting rural populations, and demonstrates the need to examine rural adults separately from their urban counterparts.

Keywords: Physical activity, Rural communities, Cross-sectional study, Multilevel modelling

\footnotetext{
* Correspondence: es244@exeter.ac.uk

${ }^{1}$ Sport and Health Sciences, College of Life and Environmental Sciences,

University of Exeter, St. Luke's Campus, Heavitree Road, Exeter EX1 2LU, UK

Full list of author information is available at the end of the article
} 


\section{Background}

Physical inactivity is ranked the fourth leading risk factor for global mortality, to which six percent of all deaths are attributable [1]. Strong evidence supports the direct relationship between physical inactivity and all-cause mortality, coronary heart disease, high blood pressure, stroke, diabetes, obesity, metabolic syndrome, colon cancer, breast cancer, and depression [2]. In fact, to reduce the risk of these diseases, adults are recommended to undertake a minimum of 150 minutes of at least moderate-intensity activity per week [2,3]. Despite this, in England, only 29\% of women and 39\% of men reported doing sufficient physical activity [4], and physical inactivity is costing the United Kingdom National Health Service in excess of $£ 0.9$ billion per year [5]. Additionally, in Devon, south-west England, $17 \%$ of all deaths in 2010 could have been prevented if all adults were physically active [6].

Therefore, understanding the factors that explain why some adults are regularly active while others are inactive is of utmost importance to public health research in the United Kingdom [3]. Physical activity is a complex behaviour determined by the interaction of a large number of personal, social, and environmental factors specific to populations, setting, and type of physical activity $[7,8]$. Furthering the understanding of the factors that influence physical activity behaviour in specific populations will aid the development of effective, tailored intervention strategies aimed at increasing the population prevalence of physical activity.

The majority of physical activity studies to date have examined urban populations [9]. When examining the influence of residential location on physical activity, most studies have found that rural adults are less likely to meet recommended physical activity guidelines than urban adults, making rural residents appropriate targets for future physical activity interventions [10-14]. Several studies have highlighted differences between urban and rural adults. For instance, Parks, Housemann, and Brownson [12] found noticeable differences in the importance of places to exercise on physical activity behaviour. Access to parks, walking trails, and exercise equipment was found to be important for urban adults, while access to neighbourhood streets for activity, and an indoor gym were more important for rural adults [12]. Younger age, fewer barriers to leisure time activity, and social support have been reported as correlates of physical activity in urban women, compared to higher educational attainment and the presence of enjoyable scenery for rural women [11]. Residents of rural areas are also more likely than their urban/suburban counterparts to report lower social support, limited access to exercise facilities, and fewer pavements as barriers to being physically active [11,12]. Eyler [15] found that the most frequently reported barrier to being physically active among rural women was the remoteness and how rural the local area was although neither of these factors were associated with reported activity. Previous research has indicated that being too far from activity facilities is a major barrier for women living in rural areas $[16,17]$. Most studies that have focused on rural areas have examined communities from the United States, where it is often the case that rural dwellers are of lower socioeconomic status than urban residents [18], which may explain some of the differences in physical activity behaviour compared to urban areas. Generally in England, however, people living in rural areas are often among the most affluent [19]. Across the south-west of England, out of the 300 most deprived areas only 11 were classified as rural [20]. Regardless, it is clear that rural populations face a unique set of challenges associated with physical activity behaviour, and they are clearly understudied in the United Kingdom. Little is known about the correlates of physical activity in adults living in rural villages in the United Kingdom and whether they are different from the correlates reported by urban residents.

The aim of this study was to identify the correlates of physical activity behaviour in adults residing in rural villages in south-west England. The association of personal, social, perceived environmental, and village level factors with selfreported physical activity outcomes was examined.

\section{Methods}

\section{Recruitment and participants}

This study uses baseline data from the first time period of a stepped wedge cluster randomised controlled trial evaluating the effectiveness of a community-level physical activity intervention [21]. The study was conducted in 128 rural villages across Devon, south-west England, each with a population size between 500 and 2000 people. These criteria were set so that villages were large enough to have local facilities suitable for physical activity, but limited in the amount of activity opportunities they offered. The addresses of all households in Devon were purchased from a private company (Address List Utility, Arc en Ciel, Version 3.1 PAF Quarter 1, 2011) and used to generate a complete list of all households within the study villages. From the list, a random sample of households, stratified by village, was selected to receive a survey questionnaire via the post. Households were sent a questionnaire, a participant information sheet and a prepaid return envelope. The adult in each household who had most recently had a birthday was invited to complete the survey. Eligible participants were aged 18 years or over and resident in the household.

The survey consisted of 28 questions and took participants approximately 10-15 minutes to complete, based on estimates obtained during pilot work. Informed consent was implied when participants returned a completed questionnaire. In total, 2,415 adults aged 18 to 
102 years returned a questionnaire and formed the sample for the study.

\section{Measures}

\section{Physical activity}

Physical activity was measured using the self-administered, short version of the International Physical Activity Questionnaire (IPAQ-SV) [22]. The IPAQ-SV includes seven items collecting information on the frequency and duration of physical activities undertaken in the previous seven days (vigorous-intensity activity, moderate-intensity activity, walking, and sitting behaviour). The IPAQ-SV has been rigorously tested for reliability and validity [22-24].

Participants were categorised according to whether they did sufficient physical activity to meet the current United Kingdom physical activity guidelines (at least 150 minutes of moderate-intensity activity per week in bouts of 10 minutes or more, or at least 75 minutes of vigorousintensity activity per week: [3]). Physical activity level was also analysed using metabolic equivalent (MET) values to calculate participants' total MET-minutes per week of moderate intensity walking, moderate intensity physical activity, and vigorous intensity physical activity, using the IPAQ-SV scoring methods for calculating physical activity levels [25].

\section{Demographic characteristics}

Participants were asked to report their gender, age, health status, dog ownership, number of children, and cars in the household. These were based on questions from the Health Survey for England [4], apart from the dog ownership question that was taken from an Australian cohort study [26]. Body mass index (BMI), defined as weight (kg) divided by height squared $\left(\mathrm{m}^{2}\right)$, was calculated from participants' self-reported height and weight.

\section{Social factors}

To assess social factors, measures were created based on a multi-national motivation for change scale [27], and a scale developed for use in an Australian cohort study [26] (Table 1). For the 'commitment to doing more physical activity' variable, the mean was calculated across the three constituent items, and the resulting variable was categorised based on the tertiles (low, moderate, and high). The mean scores were calculated from the constituent items for the 'physical activity social norms', 'physical activity habit', and 'physical activity village supportiveness' variables, and then categorised into "Unfavourable" $(<0)$, "Neutral" $(0)$, and "Favourable" $(>0)$.

\section{Perceived local environmental characteristics}

Perceived local environmental characteristics were measured using items previously developed for use in a United Kingdom health study, and found to have acceptable levels of test-retest reliability [28] (Table 1). Perceived proximity and use of different recreational facilities were measured in the survey using scales that were previously found to have acceptable test-retest reliability [26,29] (Table 1). The means were calculated from the constituent items for the variables measuring 'traffic and pleasantness of surroundings', 'proximity and convenience of walking', 'safety and convenience of cycling,' 'convenience of public transport', and 'safety of walking after dark', and were then categorised into "Unfavourable" $(<0)$, "Neutral" (0), and "Favourable" (>0).

\section{Village-level factors}

Five village-level factors were examined: population density [30], mean age of villagers [31], percent of villagers that were male [30], Indices of Multiple Deprivation (higher scores indicates more deprived [32]), and the dominant Sport England Market Segmentation for each village [33]. The Sport England Market Segmentation divides the English adult population into 19 market segments based on their sports participation, motivations, and barriers to doing more sport, allowing Local Authorities, Sport National Governing Bodies and sports clubs to profile both individuals and areas.

\section{Sample size}

Power calculations were based on the intervention study [21]. It was estimated that 10 participants would need to be recruited from each of the 128 villages at each stage of the stepped wedge trial, in order to achieve $80 \%$ power at the $5 \%$ significance level, based on detecting an increase from $25 \%$ to $30 \%$ in the proportion of participants that met the recommended activity guidelines [34]. A recent pilot for a population study of travel behaviour in the United Kingdom achieved a response rate of $17 \%$ for a short questionnaire postal survey [35]. Using this as a guide, 50 surveys were sent out to each of the 128 villages, anticipating that we would obtain at least 10 responses per village. If the number of completed questionnaires returned within three weeks of the initial mailing was insufficient for a given village, additional questionnaires were sent out to new households.

\section{Statistical analysis}

Random effects ("multilevel") logistic regression was used to examine whether the personal, social, environmental, and village-level factors were associated with meeting the recommended physical activity guideline (binary outcome). Random effects linear regression was used to study the relationship of the same factors with MET-minutes of moderate-vigorous physical activity per week (continuous outcome). These methods take account of correlation between responses of participants in the same village (clustering). Firstly, crude (unadjusted) models were fitted 


\section{Table 1 Survey measures}

\section{Psychosocial factors}

Commitment to doing more physical activity (3 items - rated from 0 "not at all" to 10 "very much so" [28])

How important is it for you to do more physical activity than you do now?

How confident are you that you could do more physical activity if you decided to?

To what extent are you trying to do more physical activity?

Physical activity social norms (2 items - rated from -2 "strongly disagree" to +2 "strongly agree" [25])

My family is interested in physical activity/sport

People around my village all seem to be exercising these days

Physical activity habit ( 3 items - rated from -2 "strongly disagree" to +2 "strongly agree" [25])

I find it easy to have a go at physical activities

I have always done some kind of physical activity

In the last 2 years, I have been involved in regular physical activity at one time or another

Physical activity village supportiveness (3 items - rated from -2 "strongly disagree" to +2 "strongly agree" [25])

I have recently had opportunities to get involved in physical activity

My village is a good place to be physically active

There are very few opportunities to be physically active in my village

\section{Perceived local environmental characteristics}

\section{Perceptions of the local area (5 factors)}

Traffic and pleasantness of surroundings ( 4 items rated from -2 "strongly disagree" to +2 "strongly agree" [26])

It is pleasant to walk in the local area

There is a lot of traffic noise in the local area

There is little traffic in the local area

It is safe to cross the road in the local area

Proximity and convenience of walking (4 items rated from -2 "strongly disagree" to +2 "strongly agree" [26])

There is a park within walking distance

The nearest shops are too far to walk to

There are no convenient routes for walking in the local area

There are no pavements in the local area

Safety and convenience of cycling ( 2 items - rated from -2 "strongly disagree" to +2 "strongly agree" [26])

The roads are dangerous for cyclists in the local area

There are convenient routes for cycling in the local area

Convenience of public transport ( 1 item - rated from -2 "strongly disagree" to +2 "strongly agree" [26])
Table 1 Survey measures (Continued)

Safety of walking after dark (1 item - rated from -2

"strongly disagree" to +2 "strongly agree" [26])

Presence of recreational facilities within the local area (3 factors)

Manmade sports facilities in local area

(4 items - responses 1 "yes" versus 2 "no" [25])

Sporting club/recreation centre/gym

Public swimming pool

Public tennis/squash courts

Indoor sports facilities (e.g., sports hall)

Natural activity facilities in local area (3 items responses 1 "yes" versus 2 "no" [25])

Walking routes/footpaths

Local park/public green space

River/beach/waterfront

Community centre/village hall in local area

(1 item - responses 1 "yes" versus 2 "no" [25])

Use of recreational facilities (8 items - responses 0 "no, not in the last year", 1 "yes, in last 12 months" or 2 "yes, in last month" [27])

Walking routes/footpaths

Local park/public green space

Sporting club/recreation centre/gym

River/beach/waterfront

Public swimming pool

Public tennis/squash courts

Indoor sports facility (e.g., sports hall)

Community centre/village hall

Locality of facilities used (8 items - response box for participant to name location of facility used [27])

Walking routes/footpaths

Local park/public green space

Sporting club/recreation centre/gym

River/beach/waterfront

Public swimming pool

Public tennis/squash courts

Indoor sports facility (e.g., sports hall)

Community centre/village hall

separately for each factor as the sole predictor in the analysis. Partially adjusted models were then fitted for each type of factor, using as predictors those that were significant at the 5\% level in the unadjusted analyses (e.g., a model was fitted with significant personal factors only). Finally, a single fully adjusted model was fitted including all factors of all types that were significant predictors in the partially adjusted models. Only estimates from the unadjusted and fully adjusted models are reported. The tabulated findings are based on analyses of males and females together. Tests of interaction were carried out to assess evidence of differential effects between the 
gender groups and where found these are commented on in the text. All analyses were carried out using Stata 12.1 software [36].

\section{Results}

Initially, 6,400 surveys were sent out, with an additional 10 surveys sent out after three weeks because two villages had not achieved their quota of 10 completed responses. The median number of completed responses per village was 18 (range 11 to 31). 2415 responses were received in total, achieving a response rate of $37.7 \%$. The majority of respondents were female $(62.7 \%)$, with a mean (SD) age of 58 years (15.2). Compared to the general population of the study villages, the study participants tended to be older ( $70.2 \%$ versus $59.2 \%$ aged 50 years or over), and a greater proportion were female $(62.7 \%$ versus $51 \%)$. The study participants were equivalent to the general village population in terms of their Index of Multiple Deprivation scores (mean (SD) 15.8 (4.0) for both study sample and general village population). The study participants were also extremely similar to the general population in terms of the population density of the village they resided within (mean (SD) $0.62(0.5)$ for the study population versus $0.64(0.6)$ for the village population). Half of the participants (49.4\%) were classified as either overweight or obese, and 66.9\% of all respondents reported doing sufficient physical activity to meet the recommended guidelines, reporting a median (interquartile range) total MET-minutes of physical activity per week of 1,638 (0 to 3879; Table 2).

The dimensionality of the scales measuring 'perceptions of the local area' [28], and the 'presence of recreational facilities within the local area' [29] was examined using exploratory factor analysis with a varimax (orthogonal) rotation. Factor analysis examines whether the variation in the observed variables can be explained largely by a smaller number of underlying factors. For the scale measuring perceived environmental characteristics the scree plot indicated there were three factors "Traffic and pleasantness of surroundings", "Proximity and convenience of walking", and "Safety and convenience of cycling". Two original scale items ("Convenience of public transport" and "Safety of walking after dark") were not strongly correlated with any of the factors (factor loadings $<0.5$ ) and so were treated as separate variables. Two factors were indicated for the scale measuring availability of recreational facilities in the local area. These were "Manmade sports facilities in local area" and "Natural activity facilities in local area". The item "Community centre/village hall in local area" was treated as a separate variable, because the factor loading was less than 0.5. Composite scores were created for each of the factors, based on the mean of the items that had their primary loadings on each factor.

\section{Meets recommended activity guidelines}

The logistic regression analyses (Table 3) revealed that being male and in better health were positively associated with the odds of meeting the recommended activity guideline in the fully adjusted models. Greater commitment to doing more physical activity, favourable activity social norms, and a greater physical activity habit were associated with increased odds of being active at recommended levels in the fully adjusted model. Recent use of recreational facilities was also associated with meeting the guidelines.

'Commitment to doing more physical activity' was the only variable found to have a significant interaction with gender ( $\mathrm{p}$-value for interaction $=0.04$ ). There was little evidence of an association between commitment to doing more physical activity and meeting the recommended activity guideline for females $(\mathrm{p}=0.19)$. Males, however, with 'moderate' (adjusted OR 1.52, 95\% CI: 1.03 to 2.24) or 'high' (adjusted OR 2.64, 95\% CI: 1.59 to 4.38) commitment levels, had increased odds of meeting the guidelines, compared to those with 'low' commitment levels ( $\mathrm{p}<0.001)$.

\section{Total leisure-time physical activity}

The linear regression analyses revealed that being male, under 35, of normal body mass index, and in good health, were all associated with increased leisure-time physical activity (LTPA; Table 4). In terms of occupational activity, people with sitting or standing occupations did less MET-minutes per week of physical activity than people who were not employed. People with physical jobs did the most LTPA per week. Owning a dog was also associated with increased LTPA. Participants with moderate 'commitment to doing more physical activity' levels reported the least LTPA. Positive activity social norms and physical activity habits were associated with increased leisure-time physical activity. Inconvenience of public transport and using facilities outside the local village were both associated with increased leisure-time physical activity behaviour in the fully adjusted model.

'Convenience of public transport' was the only variable that had a significant interaction with gender ( $\mathrm{p}$-value for interaction $=0.04$ ). There was little evidence of an association between convenience of public transport and total leisure-time physical activity for females $(\mathrm{p}=0.14)$. Males, however, with 'neutral' (adjusted mean difference $=-508$, 95\% CI: -1061 to 45 ) or 'favourable' (adjusted mean difference $=-524,95 \%$ CI: -959 to -90 ) opinions about the convenience of public transport did less leisure-time physical activity than those with 'unfavourable' opinions on the convenience of public transport $(\mathrm{p}=0.03)$.

\section{Village-level factors}

None of the village-level factors were significantly associated with reported leisure-time physical activity. 
Table 2 Descriptive characteristics $(\mathrm{N}=\mathbf{2 4 1 5})$

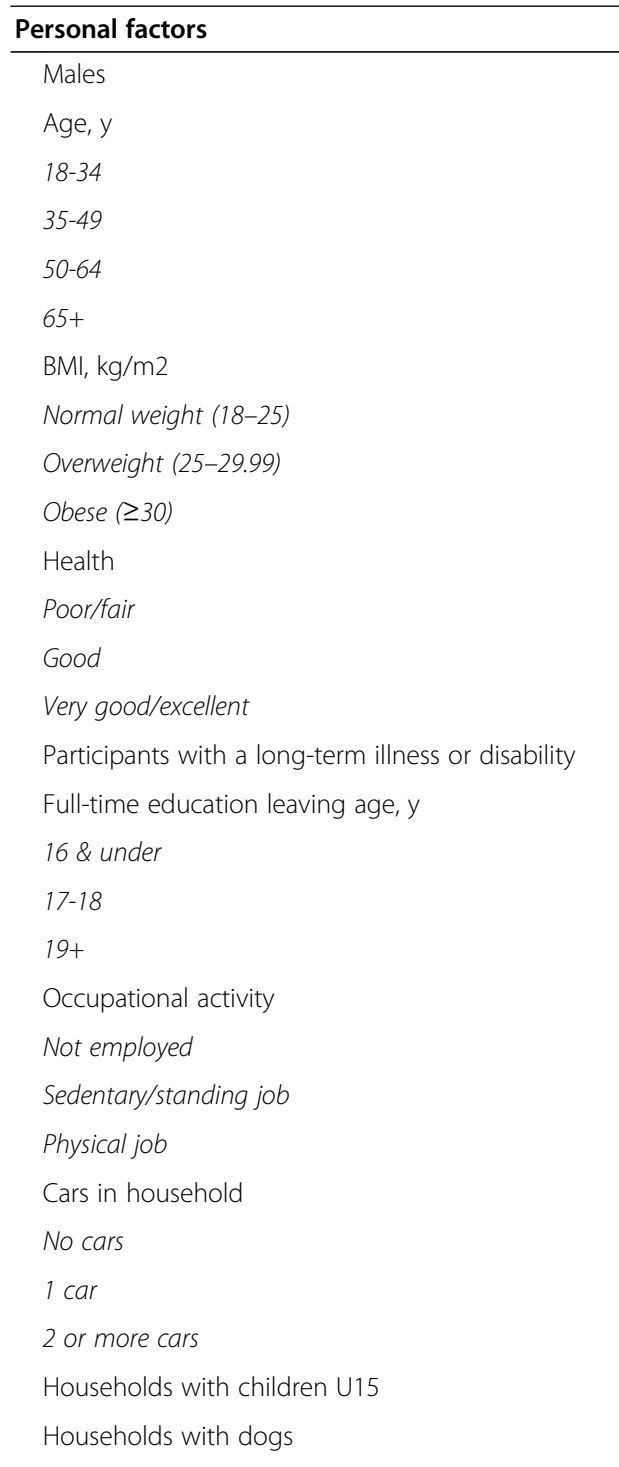

$\%$

6.8

23.5

35.7

\section{Social factors}

Commitment to doing more physical activity (tertiles)

Low

Moderate

High

Physical activity social norms

Unfavourable

27.5

Neutral

Favourable

Physical activity habit

Unfavourable

Neutral

Favourable

Physical activity village supportiveness

Unfavourable
Table 2 Descriptive characteristics $(\mathbf{N}=\mathbf{2 4 1 5}$ ) (Continued)

\begin{tabular}{ll}
\hline Neutral & 22.8 \\
Favourable & 28.1
\end{tabular}

Environmental factors

Traffic and pleasantness of surroundings

Unfavourable $\quad 12.6$

Neutral $\quad 12.3$

Favourable $\quad 75.2$

Proximity and convenience of walking

Unfavourable $\quad 37.2$

Neutral $\quad 15.7$

Favourable $\quad 47.1$

Safety and convenience of cycling

Unfavourable $\quad 32.8$

Neutral $\quad 36.9$

Favourable $\quad 30.3$

Convenience of public transport

Unfavourable $\quad 59.0$

Neutral $\quad 13.9$

Favourable $\quad 27.2$

Safety of walking after dark

Unfavourable 26.2

Neutral $\quad 16.0$

Favourable $\quad 57.8$

Manmade sports facilities in local area (at least one) 61.3

Natural activity facilities in the local area (at $\quad 97.3$ least one)

Community centre/village hall in local area $\quad 79.1$

Use of recreational facilities

No facilities used $\quad 6.5$

Used in last year only $\quad 9.5$

Used in last month $\quad 84.0$

Locality of facilities used

No facilities used $\quad 15.2$

Local village only $\quad 24.2$

Outside local village only $\quad 13.7$

Both local and not local $\quad 46.9$

Village-level factors

Population density (residents per hectare), $\quad 0.6(0.5)$ mean (SD)

Mean age, (SD)

$\%$ males in village (tertiles)

Low 35.6

Moderate $\quad 32.1$

High $\quad 32.4$

Indices of Multiple Deprivation (IMD) 
Table 2 Descriptive characteristics $(\mathbf{N}=\mathbf{2 4 1 5})$ (Continued)

\begin{tabular}{ll}
\hline $\begin{array}{l}\text { More deprived than median score for villages } \\
\text { in Devon }\end{array}$ & 49.6 \\
Sport England Segmentation & \\
3 (Chloe) & 6.9 \\
6 (Tim) & 48.8 \\
8 (Jackie) & 0.5 \\
11 (Philip) & 2.0 \\
13 (Roger \& Joy) & 10.3 \\
17 (Ralph \& Phyllis) & 27.2 \\
19 (Elsie \& Arnold) & 4.3 \\
Physical activity & \\
Meets recommended guidelines & 66.9 \\
MET-minutes/week (total LTPA), median (IQR) & 1638 (0 to 3879) \\
\hline
\end{tabular}

Sample sizes ranged from 2336 to 2415 .

\section{Ancillary analysis}

An ancillary analysis was conducted for the 'commitment to do more physical activity' variable. It was hypothesised that the lack of association between 'commitment to do more physical activity' and total reported leisure-time physical activity was due to the majority of participants being sufficiently physically active, and therefore having low commitment levels to do more physical activity. To investigate this, the unadjusted and fully adjusted regression models were repeated with only those participants who did not report doing sufficient activity to meet the recommended guidelines (Table 5). Commitment to doing more physical activity was significantly positively associated with LTPA in the unadjusted model, but not in the fully adjusted model.

\section{Village- and participant-level variation}

Only $2.4 \%$ of the variation in reported leisure-time physical activity was at the village level (i.e., $97.6 \%$ was at the participant level). The fully adjusted model explained $72.6 \%$ of the between-village variation and $18.7 \%$ of the participant-level variation in physical activity.

\section{Discussion}

The purpose of this study was to examine the personal, social, and environmental correlates of physical activity in rural adults from the United Kingdom. A number of variables were identified as correlates of physical activity behaviour. Gender, health status, commitment to doing more physical activity, social norms, physical activity habit, and reported use of recreational facilities were all associated with both meeting the recommended guidelines and total reported LTPA. Age, BMI, occupational activity, dog ownership, locality of recreational facilities, and convenience of public transport were only correlates for total LTPA.
Although cross-sectional data are useful for identifying associations, analyses of longitudinal data provide a stronger basis for inferring causality $[37,38]$. In one review, Bauman et al. [37] identified health status as one of the clearest predictors of change in physical activity behaviour in adults. There was also consistent evidence to suggest personal history of physical activity during adulthood [38,39] (similar to 'physical activity habit'), and intention to exercise [38-40] (similar to 'commitment to do more physical activity'), were both predictors of change in physical activity behaviour. Reviews suggest that social norms are not associated with physical activity behaviour [37]. Therefore, findings from the present study imply that rural populations are similar to the general population in terms of the association between health status, physical activity habit, commitment to be more active, and their reported physical activity behaviour. The association between social norms and physical activity in the present study suggests, however, that social norms may be a uniquely important factor for rural populations.

Other correlates of physical activity reported in the literature are male sex [39,40], age (negatively) [39-41], and overweight (negatively) [39]. Our findings concur with this research, although age and overweight status were only associated with total leisure-time physical activity and not the likelihood of meeting the guidelines. In line with previous research, dog owners report more physical activity than people who do not own dogs [42-44].

Accessibility of recreational facilities has been found to be the most consistent environmental predictor of physical activity and change in physical activity behaviour in reviews $[37,38,45,46]$. In the present study, how recently participants had used recreational facilities, and the locality of facilities used, were both associated with physical activity behaviour. Logically, the more recently participants had used a recreational facility, the more likely they were to have met the recommended guidelines. Research from urban populations has found that local recreational facilities are visited more frequently than those located further away $[47,48]$. In our study, the mixed outcome for locality of facilities used suggests that it is less important for rural populations where facilities are located. It may be suggested that rural adults have to travel to use facilities because there are limited facilities available within local villages. However, in fact, nearly all participants (97\%) perceived there to be at least one natural activity facility in their local area, with $61 \%$ perceiving there to be at least one man-made sports facility. It, therefore, seems that recreational facilities were available in these rural locations. Although some facilities may have been available locally, this does not necessarily mean residents used them regularly. It is plausible that if individuals had a desire to do a particular activity that was not offered locally, or had a 
Table 3 Odds ratios for meeting physical activity guidelines - logistic regression

\begin{tabular}{|c|c|c|c|c|c|c|}
\hline \multirow{2}{*}{ Predictor variable } & \multirow[b]{2}{*}{$O R$} & \multicolumn{2}{|l|}{ Unadjusted } & \multicolumn{3}{|c|}{ Fully adjusted } \\
\hline & & $95 \% \mathrm{Cl}$ & $p$ & $O R$ & $95 \% \mathrm{Cl}$ & $p$ \\
\hline \multicolumn{7}{|l|}{ Personal factors } \\
\hline Gender & & & 0.03 & & & 0.002 \\
\hline Male & & Reference & & & Reference & \\
\hline Female & 0.82 & 0.69 to 0.98 & & 0.70 & 0.55 to 0.88 & \\
\hline Age groups (years) & & & $<0.001$ & & & 0.54 \\
\hline $18-34$ & & Reference & & & Reference & \\
\hline $35-49$ & 0.87 & 0.57 to 1.33 & & 0.99 & 0.61 to 1.61 & \\
\hline $50-64$ & 0.70 & 0.47 to 1.04 & & 0.99 & 0.62 to 1.58 & \\
\hline $65+$ & 0.32 & 0.21 to 0.48 & & 0.82 & 0.50 to 1.35 & \\
\hline BMI category & & & $<0.001$ & & & 0.40 \\
\hline Normal weight & & Reference & & & Reference & \\
\hline Overweight & 0.79 & 0.65 to 0.96 & & 0.93 & 0.74 to 1.18 & \\
\hline Obese & 0.47 & 0.37 to 0.60 & & 0.81 & 0.59 to 1.10 & \\
\hline Health & & & $<0.001$ & & & $<0.001$ \\
\hline Poor/fair & & Reference & & & Reference & \\
\hline Good & 2.83 & 2.23 to 3.61 & & 1.57 & 1.14 to 2.17 & \\
\hline Very good/excellent & 5.92 & 4.66 to 7.53 & & 2.05 & 1.44 to 2.91 & \\
\hline \multicolumn{2}{|c|}{ Long-term illness/disability } & & $<0.001$ & & & 0.06 \\
\hline Yes & & Reference & & & Reference & \\
\hline No & 3.27 & 2.71 to 3.94 & & 1.31 & 0.99 to 1.73 & \\
\hline \multicolumn{2}{|c|}{ Education leaving age (years) } & & $<0.001$ & & & 0.98 \\
\hline \multicolumn{2}{|l|}{$16 \&$ under } & Reference & & & Reference & \\
\hline $17-18$ & 1.58 & 1.27 to 1.96 & & 1.02 & 0.78 to 1.34 & \\
\hline $19+$ & 1.86 & 1.52 to 2.28 & & 1.00 & 0.77 to 1.28 & \\
\hline \multicolumn{2}{|l|}{ Occupation category } & & $<0.001$ & & & \\
\hline \multicolumn{2}{|l|}{ Not employed } & Reference & & & & \\
\hline Sitting/standing job & 1.82 & 1.51 to 2.20 & & & & \\
\hline Physical job & 2.41 & 1.82 to 3.20 & & & & \\
\hline \multicolumn{2}{|l|}{ Cars in household } & & $<0.001$ & & & 0.22 \\
\hline \multicolumn{2}{|l|}{ No car } & Reference & & & Reference & \\
\hline 1 car & 4.11 & 2.55 to 6.62 & & 1.38 & 0.71 to 2.66 & \\
\hline $2+$ cars & 7.74 & 4.82 to 12.43 & & 1.61 & 0.82 to 3.17 & \\
\hline \multicolumn{2}{|c|}{ Children under 15 in household } & & $<0.001$ & & & \\
\hline \multicolumn{2}{|l|}{ Yes } & Reference & & & & \\
\hline No & 0.58 & 0.47 to 0.73 & & & & \\
\hline \multicolumn{2}{|l|}{ Dog ownership } & & $<0.001$ & & & 0.15 \\
\hline \multicolumn{2}{|l|}{ Yes } & Reference & & & Reference & \\
\hline No & 0.71 & 0.60 to 0.85 & & 0.85 & 0.68 to 1.06 & \\
\hline \multicolumn{7}{|l|}{ Social factors } \\
\hline \multicolumn{3}{|c|}{ Commitment to doing more physical activity } & $<0.001$ & & & 0.002 \\
\hline Low & & Reference & & & Reference & \\
\hline Moderate & 1.63 & 1.33 to 1.99 & & 1.21 & 0.94 to 1.55 & \\
\hline
\end{tabular}


Table 3 Odds ratios for meeting physical activity guidelines - logistic regression (Continued)

\begin{tabular}{|c|c|c|c|c|c|c|}
\hline High & 2.79 & 2.22 to 3.50 & & 1.66 & 1.25 to 2.20 & \\
\hline Physical activ & & & $<0.001$ & & & 0.004 \\
\hline Unfavourable & & Reference & & & Reference & \\
\hline Neutral & 1.43 & 1.13 to 1.80 & & 1.05 & 0.79 to 1.40 & \\
\hline Favourable & 2.53 & 2.06 to 3.11 & & 1.47 & 1.14 to 1.90 & \\
\hline Physical activ & & & $<0.001$ & & & $<0.001$ \\
\hline Unfavourable & & Reference & & & Reference & \\
\hline Neutral & 2.17 & 1.57 to 3.02 & & 1.61 & 1.12 to 2.33 & \\
\hline Favourable & 7.77 & 6.27 to 9.62 & & 4.30 & 3.33 to 5.55 & \\
\hline Physical activ & veness & & $<0.001$ & & & \\
\hline Unfavourable & & Reference & & & & \\
\hline Neutral & 1.66 & 1.33 to 2.07 & & & & \\
\hline Favourable & 1.95 & 1.57 to 2.41 & & & & \\
\hline Environmental factors & & & & & & \\
\hline Traffic and pl & undings & & 0.04 & & & \\
\hline Unfavourable & & Reference & & & & \\
\hline Neutral & 1.15 & 0.83 to 1.62 & & & & \\
\hline Favourable & 1.37 & 1.06 to 1.76 & & & & \\
\hline Proximity anc & valking & & 0.30 & & & \\
\hline Unfavourable & & Reference & & & & \\
\hline Neutral & 1.17 & 0.90 to 1.53 & & & & \\
\hline Favourable & 0.96 & 0.80 to 1.16 & & & & \\
\hline Safety and co & & & 0.96 & & & \\
\hline Unfavourable & & Reference & & & & \\
\hline Neutral & 1.02 & 0.83 to 1.25 & & & & \\
\hline Favourable & 0.98 & 0.79 to 1.22 & & & & \\
\hline Convenience & & & 0.18 & & & 0.64 \\
\hline Unfavourable & & Reference & & & Reference & \\
\hline Neutral & 0.94 & 0.73 to 1.21 & & 0.93 & 0.68 to 1.27 & \\
\hline Favourable & 0.83 & 0.68 to 1.01 & & 0.89 & 0.70 to 1.14 & \\
\hline Safety walkin & & & 0.002 & & & \\
\hline Unfavourable & & Reference & & & & \\
\hline Neutral & 0.97 & 0.75 to 1.27 & & & & \\
\hline Favourable & 1.36 & 1.11 to 1.66 & & & & \\
\hline Manmade sp & al area & & $<0.001$ & & & \\
\hline $1+$ facility & & Reference & & & & \\
\hline No facilities & 0.72 & 0.60 to 0.85 & & & & \\
\hline Natural activi & area & & $<0.001$ & & & \\
\hline $1+$ facility & & Reference & & & & \\
\hline No facilities & 0.35 & 0.22 to 0.58 & & & & \\
\hline Community & & & $<0.001$ & & & \\
\hline Yes & & Reference & & & & \\
\hline No & 0.66 & 0.54 to 0.82 & & & & \\
\hline Use of recrea & & & $<0.001$ & & & 0.01 \\
\hline
\end{tabular}


Table 3 Odds ratios for meeting physical activity guidelines - logistic regression (Continued)

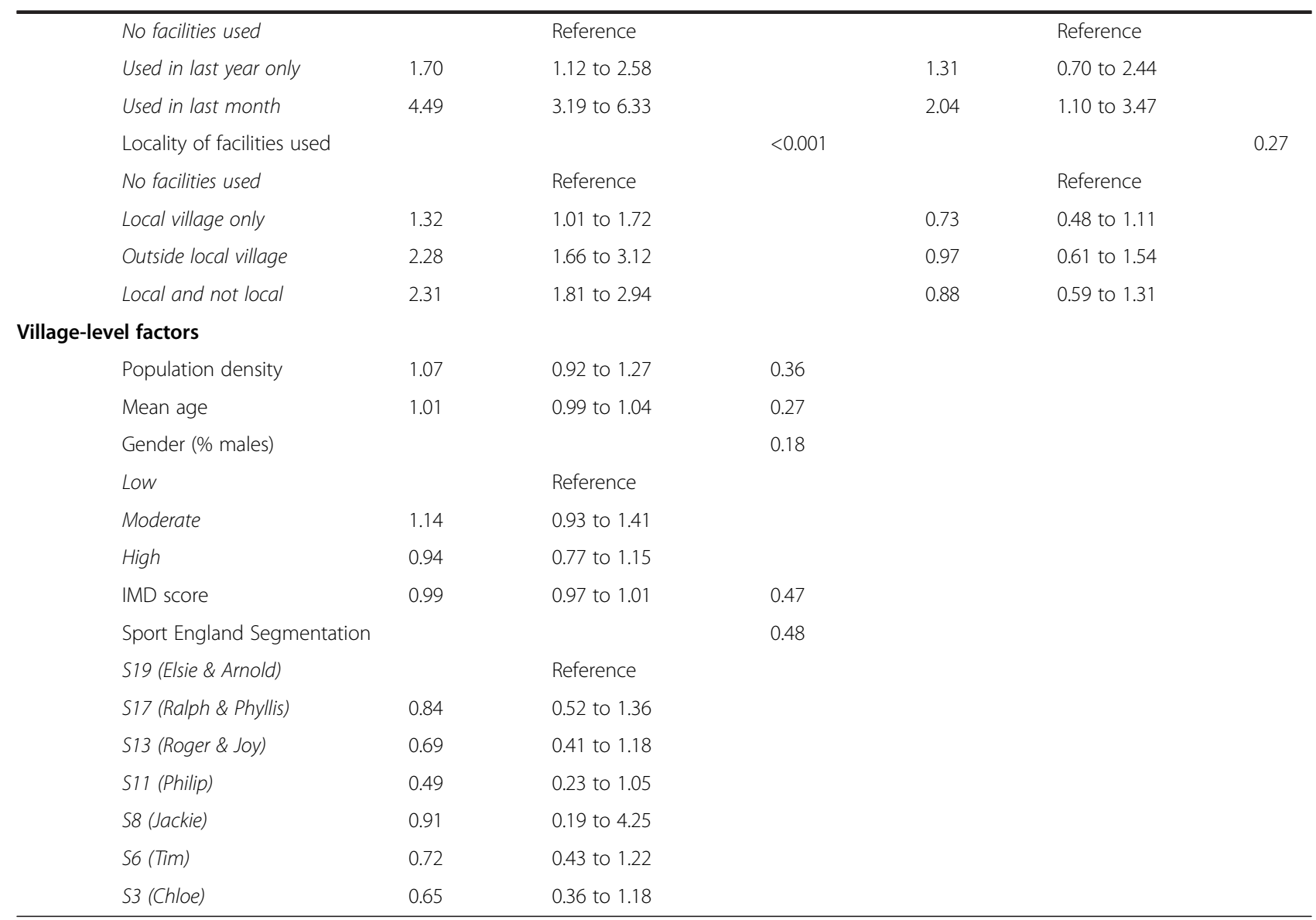

Sample sizes for the unadjusted analyses ranged from 2336 to 2415 ; sample size for the adjusted analysis was 2174 .

personal preference for a certain facility, they might have been willing to travel the necessary distance. This finding warrants further investigation, in order to understand whether rural adults would benefit from more recreational facilities in their local village.

Convenience of public transport was negatively associated with leisure-time physical activity. This finding contradicts a recent review paper that found greater access to public transport to be positively associated with walking behaviour [49]. This may be due in part to the limited public transport services available in rural Devon, with 59\% of participants reporting unfavourable responses for the convenience of public transport. Additionally, this study only measured convenience of public transport, rather than use. Thus, it may be that individuals who regularly used public transport also did more walking than individuals who did not.

\section{Strengths and limitations}

Two key strengths of this study are the large sample size $(n=2,415)$, and the random selection of participants. Additionally, the study examined a range of personal, social and perceived environmental factors, in addition to village-level factors. Although this study forms part of a longitudinal study, the data presented here are crosssectional and, therefore, can only be used to examine associations rather than to draw inferences regarding causality. Despite being better than anticipated, and comparing well with other survey studies from the United Kingdom (15.9\% [28], 17\% [35]), the response rate was low (37.7\%). This raises concerns that those who consented may not represent the wider population (non-response bias) [50]. However, the participants in the present study were similar to the wider population in terms of IMD score and the population density of the village they resided in. Compared to the wider population, however, the survey respondents tended to be older, with a greater proportion being female. Previous research suggests females and older adults are often over-represented in health surveys [4]. Two-thirds of the population reported meeting the recommended guidelines, suggesting that those of higher activity levels tend to be over-represented. Whilst an unrepresentative sample is compromised when estimating a mean or prevalence, such data are generally robust for examining relationships between variables, in this case between physical activity and potential correlates. 
Table 4 Regression coefficients for MET-minutes/week physical activity (total LTPA) - linear regression

\begin{tabular}{|c|c|c|c|c|c|c|}
\hline \multirow[b]{2}{*}{ Predictor variable } & \multirow[b]{2}{*}{ Coeff. } & \multicolumn{2}{|l|}{ Unadjusted } & \multicolumn{3}{|c|}{ Fully adjusted } \\
\hline & & $95 \% \mathrm{Cl}$ & $p$ & Coeff. & $95 \% \mathrm{Cl}$ & $p$ \\
\hline \multicolumn{7}{|l|}{ Personal factors } \\
\hline Gender & & & $<0.001$ & & & $<0.001$ \\
\hline Male & & Reference & & & Reference & \\
\hline Female & -519 & -763 to -274 & & -597 & -841 to -352 & \\
\hline Age groups (years) & & & $<0.001$ & & & 0.002 \\
\hline $18-34$ & & Reference & & & Reference & \\
\hline $35-49$ & -864 & -1378 to -351 & & -694 & -1182 to -206 & \\
\hline $50-64$ & -596 & -1088 to -103 & & -368 & -843 to 108 & \\
\hline $65+$ & -1249 & -1744 to -754 & & -787 & -1318 to -255 & \\
\hline BMI Category & & & $<0.001$ & & & 0.02 \\
\hline Normal weight & & Reference & & & Reference & \\
\hline Overweight & -540 & -804 to -277 & & -365 & -618 to -111 & \\
\hline Obese & -879 & -1232 to -525 & & -195 & -540 to 151 & \\
\hline Health & & & $<0.001$ & & & $<0.001$ \\
\hline Poor/Fair & & Reference & & & Reference & \\
\hline Good & 939 & 601 to 1278 & & 505 & 153 to 857 & \\
\hline ExcellentNery good & 1765 & 1444 to 2086 & & 836 & 481 to 1190 & \\
\hline Long-term Illness/Disability & & & $<0.001$ & & & \\
\hline Yes & & Reference & & & & \\
\hline No & & 687 to 1208 & & & & \\
\hline Education leaving age (years) & & & 0.004 & & & \\
\hline $16 \&$ under & & Reference & & & & \\
\hline $17-18$ & 449 & 146 to 752 & & & & \\
\hline $19+$ & 379 & 103 to 654 & & & & \\
\hline Occupation category & & & $<0.001$ & & & $<0.001$ \\
\hline Not employed & & Reference & & & Reference & \\
\hline Sitting/standing job & -84 & -341 to 173 & & -526 & -831 to -222 & \\
\hline Physical job & 1274 & 921 to 1627 & & 530 & 147 to 912 & \\
\hline Cars in household & & & $<0.001$ & & & \\
\hline No car & & Reference & & & & \\
\hline 1 car & 1143 & 516 to 1770 & & & & \\
\hline $2+$ cars & 1627 & 1009 to 2244 & & & & \\
\hline Children under 15 in household & & & 0.98 & & & \\
\hline Yes & & Reference & & & & \\
\hline No & -4 & -292 to 285 & & & & \\
\hline Dog ownership & & & $<0.001$ & & & 0.03 \\
\hline Yes & & Reference & & & Reference & \\
\hline No & -527 & -770 to -284 & & -262 & -501 to -23 & \\
\hline \multicolumn{7}{|l|}{ Social factors } \\
\hline $\begin{array}{l}\text { Commitment to doing more physical } \\
\text { activity }\end{array}$ & & & 0.002 & & & 0.03 \\
\hline Low & & Reference & & & Reference & \\
\hline
\end{tabular}


Table 4 Regression coefficients for MET-minutes/week physical activity (total LTPA) - linear regression (Continued)

\begin{tabular}{|c|c|c|c|c|c|c|}
\hline Moderate & -114 & -398 to 170 & & -317 & -599 to -36 & \\
\hline High & 403 & 111 to 696 & & 18 & -286 to 322 & \\
\hline Physical activity social norms & & & $<0.001$ & & & $<0.001$ \\
\hline Unfavourable & & Reference & & & Reference & \\
\hline Neutral & 474 & 140 to 807 & & 154 & -170 to 478 & \\
\hline Favourable & 1096 & 813 to 1379 & & 513 & 228 to 799 & \\
\hline Physical activity habit & & & $<0.001$ & & & $<0.001$ \\
\hline Unfavourable & & Reference & & & Reference & \\
\hline Neutral & 814 & 361 to 1267 & & 447 & -16 to 910 & \\
\hline Favourable & 2245 & 1974 to 2516 & & 1557 & 1244 to 1870 & \\
\hline Physical activity village supportiveness & & & $<0.001$ & & & \\
\hline Unfavourable & & Reference & & & & \\
\hline Neutral & 409 & 109 to 708 & & & & \\
\hline Favourable & 553 & 273 to 833 & & & & \\
\hline \multicolumn{7}{|l|}{ Environmental factors } \\
\hline Traffic and pleasantness of surroundings & & & 0.06 & & & \\
\hline Unfavourable & & Reference & & & & \\
\hline Neutral & -139 & -618 to 339 & & & & \\
\hline Favourable & 257 & -110 to 624 & & & & \\
\hline Proximity and convenience of walking & & & 0.02 & & & \\
\hline Unfavourable & & Reference & & & & \\
\hline Neutral & 397 & 37 to 757 & & & & \\
\hline Favourable & -83 & -351 to 185 & & & & \\
\hline Safety and convenience of cycling & & & 0.14 & & & \\
\hline Unfavourable & & Reference & & & & \\
\hline Neutral & 109 & -176 to 395 & & & & \\
\hline Favourable & 304 & -1 to 608 & & & & \\
\hline Convenience of public transport & & & 0.06 & & & 0.04 \\
\hline Unfavourable & & Reference & & & Reference & \\
\hline Neutral & -25 & -382 to 332 & & -52 & -391 to 287 & \\
\hline Favourable & -336 & -619 to -52 & & -348 & -617 to -80 & \\
\hline Safety walking after dark & & & 0.003 & & & 0.22 \\
\hline Unfavourable & & Reference & & & Reference & \\
\hline Neutral & -224 & -601 to 152 & & -90 & -451 to 271 & \\
\hline Favourable & 304 & 24 to 585 & & 164 & -108 to 436 & \\
\hline Manmade sports facilities in local area & & & 0.06 & & & \\
\hline $1+$ facility & & Reference & & & & \\
\hline No facilities & -240 & -493 to 14 & & & & \\
\hline Natural activity facilities in local area & & & 0.02 & & & \\
\hline $1+$ facility & & Reference & & & & \\
\hline No facilities & -864 & -1592 to -135 & & & & \\
\hline Community centre in local area & & & 0.003 & & & 0.11 \\
\hline Yes & & Reference & & & Reference & \\
\hline No & -450 & -749 to -152 & & -239 & -527 to 50 & \\
\hline
\end{tabular}


Table 4 Regression coefficients for MET-minutes/week physical activity (total LTPA) - linear regression (Continued)

\begin{tabular}{|c|c|c|c|c|c|c|}
\hline Use of recreational facilities & & & $<0.001$ & & & 0.05 \\
\hline No facilities used & & Reference & & & Reference & \\
\hline Used in last year only & 69 & -530 to 668 & & -126 & -833 to 580 & \\
\hline Used in last month & 1083 & 605 to 1561 & & 351 & -294 to 997 & \\
\hline Locality of facilities used & & & 0.001 & & & 0.007 \\
\hline No facilities used & & Reference & & & Reference & \\
\hline Local village only & 43 & -344 to 429 & & -263 & -714 to 189 & \\
\hline Outside local village & 775 & 330 to 1220 & & 297 & -198 to 791 & \\
\hline Local and not local & 318 & -30 to 666 & & -286 & -709 to 137 & \\
\hline \multicolumn{7}{|l|}{ Village-level factors } \\
\hline Population density & 20 & -242 to 281 & 0.88 & & & \\
\hline Mean age & 14 & -28 to 56 & 0.52 & & & \\
\hline Gender ( $\%$ males) & & & 0.24 & & & \\
\hline Low & & Reference & & & & \\
\hline Moderate & 294 & -49 to 636 & & & & \\
\hline High & 125 & -218 to 469 & & & & \\
\hline IMD score & 3 & -32 to 39 & 0.85 & & & \\
\hline Sport England Segmentation & & & 0.38 & & & \\
\hline S19 (Elsie \& Arnold) & & Reference & & & & \\
\hline S17 (Ralph \& Phyllis) & -46 & -779 to 688 & & & & \\
\hline S13 (Roger \& Joy) & -127 & -948 to 695 & & & & \\
\hline S11 (Philip) & -567 & -1810 to 676 & & & & \\
\hline S8 (Jackie) & 1091 & -1187 to 3369 & & & & \\
\hline S6 (Tim) & & -260 & -1064 to 544 & & & \\
\hline S3 (Chloe) & -652 & -1592 to 288 & & & & \\
\hline
\end{tabular}

Sample sizes for the unadjusted analyses ranged from 2336 to 2415; sample size for the adjusted analysis was 2179.

A further limitation of this study is the use of selfreported data. We used established and validated measures where possible, but although the IPAQ-SV has been found to have acceptable levels of test-retest reliability $(r=0.76)$ [23], recent reviews have questioned its levels of criterion validity $(\rho=0.30,95 \%$ CI 0.23 to 0.36 [22]; median $\rho=0.29$, range 0.09 to 0.39 [24]). Self-report measures of physical activity tend to include bias due to social desirability and participants may find it difficult

Table 5 Regression coefficients for MET-minutes/week physical activity (participants who didn't meet the recommended guidelines) - linear regression

\begin{tabular}{|c|c|c|c|c|c|c|}
\hline \multirow[b]{2}{*}{ Predictor variable } & \multirow[b]{2}{*}{ Coeff. } & \multicolumn{3}{|c|}{ Unadjusted } & \multicolumn{2}{|c|}{ Fully adjusted } \\
\hline & & $95 \% \mathrm{Cl}$ & $p$ & Coeff. & $95 \% \mathrm{Cl}$ & $p$ \\
\hline $\begin{array}{l}\text { Commitment } \\
\text { to doing more } \\
\text { physical activity }\end{array}$ & & & $<0.001$ & & & 0.19 \\
\hline Low & & Reference & & & Reference & \\
\hline Moderate & 47 & 15 to 80 & & 10 & -26 to 46 & \\
\hline High & 99 & 60 to 137 & & 40 & -4 to 85 & \\
\hline
\end{tabular}

to recall activities from the past seven days. The fact that self-reported height and weight were used to calculate body mass index is another limitation, because of social desirability bias to over-report height and underreport weight [51]. Despite this, Goodman and Strauss [52] stated that self-report measures are acceptable in epidemiological studies given that self-report measures are correlated with measured height and weight. Finally, participants were not asked about their ethnic origin in the questionnaire. This was, however, a deliberate decision, because only $2.5 \%$ of the rural population of Devon is from non-white British ethnic groups [53].

\section{Implications}

Despite the noted limitations, our findings are important from a public health perspective, in terms of understanding the unique characteristics of rural populations, through focusing on the personal, social, and environmental correlates of physical activity. Regular physical activity plays a key role in reducing the risk factors for several chronic conditions. Therefore, the identification of physical activity correlates may help researchers, clinicians, and health 
policy makers to design population-specific interventions. This study adds to the limited research available on physical activity in rural communities from England. The results from the present study suggest that rural populations are similar to urban populations in terms of the correlates of physical activity behaviour. However, our findings do imply that social norms may be more influential for rural populations, compared to their urban counterparts. Contradictory to research from urban populations, there was a negative association between convenience of public transport and physical activity, and the most active individuals used recreational facilities exclusively outside of their local area. These findings suggest that rural and urban adults differ in terms of the way they interact with their environment, and that differences in the built environment have an influence on physical activity behaviour. To successfully change physical activity prevalence in rural populations, interventions should be tailored to modify the correlates of physical activity behaviour that are specific to rural adults, as identified in the present study.

\section{Future research}

Future research should focus on longitudinal studies with rural populations to examine the determinants of physical activity behaviour, to aid the understanding of the causal role and direction of effect of correlates. It is also recommended that the physical activity correlates from this and other similar studies be used to help develop future physical activity interventions specifically tailored to rural communities, and that rigorous evaluation methods be undertaken to determine the effectiveness of such programmes.

\section{Conclusions}

This study aimed to examine the personal, social and environmental correlates of physical activity behaviour in rural adults from south-west England. Both individual and village-level predictors were included in the analysis, with gender, health, commitment to being more active, activity habits, social norms, and use of recreational facilities revealed as the clearest correlates of physical activity behaviour. Although most of the results were in line with previous research, this study did highlight some unique characteristics of the rural population. Understanding the correlates that influence physical activity behaviour is important for the designing of effective physical activity interventions, but generally the relationship between these correlates is complex and typically understudied, especially in rural populations.

\section{Abbreviations}

BMI: Body mass index; IPAQ-SV: International physical activity questionnaire short version; LTPA: Leisure-time physical activity; MET: Metabolic equivalent.

\section{Competing interests}

The authors declare that they have no competing interests.

\section{Authors' contributions}

The study's chief investigators ES, MH and TR were responsible for identifying the research question, the design of the study, obtaining ethics approval and the acquisition of funding. OCU contributed to the fine-tuning of the methodology and conducted the randomisation procedures. ES carried out the data collection and processing. OCU, BM, MH and ES contributed to the statistical analysis. All authors helped draft and revise the manuscript and approved the final version.

\section{Acknowledgements}

We thank Active Devon for their support of the research project. This research was supported by the Economic and Social Research Council under its Capacity Building Clusters Award (RES-187-24-0002). The research was also funded by the National Institute for Health Research (NIHR) Collaborations for Leadership in Applied Health Research and Care (CLAHRC). The views expressed in this publication are those of the authors and not necessarily those of the National Health Service, the NIHR or the Department of Health.

\section{Author details}

'Sport and Health Sciences, College of Life and Environmental Sciences, University of Exeter, St. Luke's Campus, Heavitree Road, Exeter EX1 2LU, UK. ${ }^{2}$ PenCLAHRC, University of Exeter Medical School, Veysey Building, Salmon Pool Lane, Exeter EX2 4SG, UK.

Received: 10 July 2013 Accepted: 18 November 2013

Published: 21 November 2013

\section{References}

1. World Health Organization: Global Health Risks: Mortality and burden of disease attributable to selected major risks. Geneva: World Health Organization; 2009.

2. World Health Organization: Global Recommendations on Physical Activity for Health. Geneva: World Health Organization; 2010.

3. Department of Health: Physical Activity, Health Improvement and Protection: Start Active, Stay Active: A report on physical activity from the four home countries' Chief Medical Officers. London: Department of Health; 2011.

4. Craig R, Mindell J, Hirani V: Health Survey for England 2008, Volume 1: Physical activity and fitness. London: National Centre for Social Research; 2009.

5. Scarborough P, Bhatnagar P, Wickramasinghe KK, Allender S, Foster C, Rayner M: The economic burden of ill health due to diet, physical inactivity, smoking, alcohol and obesity in the UK: an update to 2006-07 NHS costs. J Public Health 2011, 33(4):527-535.

6. Public Health England: developed and supported by SWPHO: Sustrans and the South West Public Health training scheme. www.apho.org.uk/addons/_ 122359/atlas.html.

7. Sallis JF, Owen N: Ecological models. In Health Behaviour and Health Education: Theory, Research, and Practice. 2nd edition. Edited by Glanz KM, Lewis F, Rimer BK. San Francisco: Jossey-Bass; 1997:403-424.

8. Oliveira-Brochado A, Oliveira-Brochado F, Quelhas Brito P: Effects of personal, social and environmental factors on physical activity behavior among adults. Rev Port Saude Publica 2010, 28(1):7-17.

9. Yousefian A, Hennessy E, Umstattd MR, Economos CD, Hallam JS, Hyatt RR, Hartley D: Development of the rural active living assessment tools: measuring rural environments. Prev Med 2010, 50(S1):S86-S92.

10. Brownson RC, Eyler AA, King AC, Brown DR, Shyu YL, Sallis JF: Patterns and correlates of physical activity among US women 40 years and older. Am J Public Health 2000, 90(2):264-270.

11. Wilcox S, Castro C, King AC, Housemann R, Brownson RC: Determinants of leisure time physical activity in rural compared with urban older and ethnically diverse women in the United States. J Epidemiol Community Health 2000, 54:667-672.

12. Parks SE, Housemann RA, Brownson RC: Differential correlates of physical activity in urban and rural adults of various socioeconomic backgrounds in the United States. J Epidemiol Community Health 2003, 57:29-35.

13. Bertrais S, Preziosi P, Mennen L, Galan P, Hercberg S, Oppert J-M: Sociodemographic and geographic correlates of meeting current recommendations for physical activity in middle-age French adults: the 
Supplementation en Vitamines et Mineraux Antioxydants (SUVIMAX) Study. Am J Public Health 2004, 94(9):1560-1566.

14. Martin SL, Kirkner GJ, Mayo K, Matthews CE, Durstine JL, Hebert JR: Urban, rural, and regional variations in physical activity. J Rural Health 2005, 21:239-244.

15. Eyler AA: Personal, social, and environmental correlates of physical activity in rural Midwestern white women. Am J Prev Med 2003, 25(3 Suppl 1):86-92.

16. Brownson RC, Housemann RA, Brown DR, Jackson-Thompson J, King AC Malone BR, Sallis JF: Promoting physical activity in rural communities: walking trail access, use, and effects. Am J Prev Med 2000, 18(3):235-241.

17. Eyler AA, Matson-Koffman D, Evenson K, Sanderson B, Thomson J, Wilbur J, Wilcox S, Rohm-Young D: Environmental, policy, and cultural barriers to physical activity in a diverse sample of women: the Women's Cardiovascular Health Network Project - Summary and Discussion. Women Health 2002, 36(2):123-134.

18. Singh GK: Area Deprivation and Widening Inequalities in US Mortality, 1969-1998. Am J Public Health 2003, 93:1137-1143.

19. Department for Communities and Local Government: English indices of deprivation 2010: Statistics on relative levels of deprivation in England. London: Department for Communities and Local Government; 2011.

20. Oxford Consultants for Social Inclusion (OCSI): Rural deprivation in the South West. London: Oxford Consultants for Social Inclusion; 2009.

21. Solomon E, Rees T, Ukoumunne OC, Hillsdon M: The Devon Active Villages Evaluation (DAVE) trial: study protocol of a stepped wedge cluster randomised trial of a community-level physical activity intervention in rural southwest England. BMC Public Health 2012, 12:581.

22. Craig CL, Marshall AL, Sjostrom M, Bauman AE, Booth ML, Ainsworth BE, Pratt M, Ekelund U, Yngve A, Sallis JF, Oja P: International physical activity questionnaire: 12-country reliability and validity. Med Sci Sports Exerc 2003, 35:1381-1395.

23. Helmerhorst HJ, Brage S, Warren J, Besson H, Ekelund U: A systematic review of reliability and objective criterion-related validity of physical activity questionnaires. Int I Behav Nutr Phys Act 2012, 9:103.

24. Lee PH, Macfarlane DJ, Lam TH, Stewart SM: Validity of the internationa physical activity questionnaire short form (IPAQ-SF): a systematic review. Int J Behav Nutr Phys Act 2011, 8:115.

25. International Physical Activity Questionnaire: Guidelines for Data Processing and Analysis of the International Physical Activity Questionnaire (IPAQ): Short and Long Forms; 2005. https:/sites.google.com/site/theipaq/scoring-protocol.

26. Burton NW, Oldenburg B, Sallis JF, Turrell G: Measuring psychological, social, and environmental influences on leisure-time physical activity among adults. Aust N Z J Public Health 2007, 31:36-43.

27. Miller WR, Johnson WR: A natural language screening measure for motivation to change. Addict Behav 2008, 33:1177-1182.

28. Ogilvie D, Mitchell R, Mutrie N, Petticrew M, Platt S: Perceived characteristics of the environment associated with active travel: development and testing of a new scale. Int J Behav Nutr Phy Act 2008, 5:32.

29. Sallis JF, Johnson MF, Calfas KJ, Caparosa S, Nichols JF: Assessing perceived physical environmental variables that may influence physical activity. Res Q Exercise Sport 1997, 68:345-351.

30. Office for National Statistics: 2011 Census. www.ons.gov.uk/ons/guidemethod/census/2011/index.html.

31. Devon County Council. www.devon.gov.uk.

32. English Indices of Deprivation. https://www.gov.uk/government/publications/ english-indices-of-deprivation-2010-guidance.

33. Sport England. www.sportengland.org/research/about-our-research/marketsegmentation/.

34. Hussey MA, Hughes JP: Design and analysis of stepped wedge cluster randomized trials. Contemp Clin Trials 2007, 28:182-191.

35. Sahlqvist S, Song Y, Bull F, Adams E, Preston J, Ogilvie D: Effect of questionnaire length, personalisation and reminder type on response rate to a complex postal survey: randomised controlled trial. BMC Med Res Methodol 2011, 11:62.

36. StataCorp: Stata Statistical Software: Release 12. College Station, TX StataCorp LP; 2011.

37. Bauman A, Reis RS, Sallis JF, Wells JC, Loos RJF, Martin BW, for the Lancet Physical Activity Series Working Group: Correlates of physical activity: why are some people physically active and others not? Lancet 2012, 380:258-271.

38. Van Stralen MM, de Vries H, Muddle AN, Bolman C, Lechner L: Determinants of initiation and maintenance of physical activity among older adults: a literature review. Health Psychol Rev 2009, 3:147-207.
39. Trost SG, Owen N, Bauman AE, Sallis JF, Brown W: Correlates of adults' participation in physical activity: review and update. Med Sci Sports Exerc 2002, 34(12):1996-2001.

40. Rhodes RE, Martin AD, Taunton JE, Rhodes EC, Donnelly M, Elliot J: Factors associated with exercise adherence among older adults: an individual perspective. Sports Med 1999, 28:397-411.

41. Kaewthummanukul T, Brown KC: Determinants of employee participation in physical activity: critical review of the literature. AAOHN J 2006, 54:249

42. Cutt H, Giles-Corti B, Knuiman M, Burke V: Dog ownership, health and physical activity: a critical review of the literature. Health Place 2007, 13:261-272.

43. Cutt H, Giles-Corti B, Knuiman M, Timperio A, Bull F: Understanding Dog Owners' Increased Levels of Physical Activity: results From RESIDE. Am J Public Health 2008, 98(1):66-69.

44. Sehatzadeh B, Noland RB, Weiner MD: Walking frequency, cars, dogs, and the built environment. Transportation Research Part A: Policy and Practice 2011, 45:741-754.

45. Humpel N, Owen N, Leslie E: Environmental factors associated with adults participation in physical activity: a review. Am J Prev Med 2002, 22:58-69.

46. Wendel-Vos W, Droomers M, Kremers S, Brug J, van Lenthe F: Potential environmental determinants of physical activity in adults: a systematic review. Obes Rev 2007, 8:425-440.

47. McCormack GR, Giles-Corti B, Bulsara M, Pikora TJ: Correlates of distances traveled to use recreational facilities for physical activity behaviors. Int $J$ Behav Nutr Phy 2006, 3:18.

48. Hoehner CM, Brennan Ramirez LK, Elliott MB, Handy SL, Brownson RC Perceived and objective environmental measures and physical activity among urban adults. Am J Prev Med 2005, 28:105-116.

49. Rissel C, Curac N, Greenaway M, Bauman A: Physical Activity Associated with Public Transport Use - A Review and Modelling of Potential Benefits. Int J Environ Res Public Health 2012, 9(7):2454-2478.

50. Delgado-Rodriguez M, Llorca J: Bias. J Epidemiol Community Health 2004, 58:635-641.

51. Rowland ML: Self-reported weight and height. Am J Clin Nutr 1990, 52(6):1125-1133.

52. Goodman E, Strauss RS: Self-reported height and weight and the definition of obesity in epidemiologic studies. J Adolesc Health 2003, 33:140-141

53. Office for National Statistics: 2011 Census, Population and Household Estimates for England and Wales; 2012.

\section{doi:10.1186/1479-5868-10-129}

Cite this article as: Solomon et al.: Personal, social, and environmental correlates of physical activity in adults living in rural

south-west England: a cross-sectional analysis. International Journal of Behavioral Nutrition and Physical Activity 2013 10:129.

\section{Submit your next manuscript to BioMed Central and take full advantage of:}

- Convenient online submission

- Thorough peer review

- No space constraints or color figure charges

- Immediate publication on acceptance

- Inclusion in PubMed, CAS, Scopus and Google Scholar

- Research which is freely available for redistribution 